\title{
Cortical visuomotor interactions in Freezing of Gait: A TMS approach
}

\section{Gionata Strigaro}

gionata.strigaro@gmail.com

\section{Paolo Barbero}

Chiara Pizzamiglio

Luca Magistrelli

Benedetta Gori

Cristoforo Con

Claudia Varrasi

Roberto Cantello

Department of Translational Medicine, Section of Neurology, University of Piemonte Orientale and "Maggiore della Carità" University Hospital, Novara, Italy

*Corresponding author at: Department of Translational Medicine, Section of Neurology, University of Piemonte Orientale “A. Avogadro”, Via Solaroli 17, 28100 Novara, Italy.

Summary

Objectives

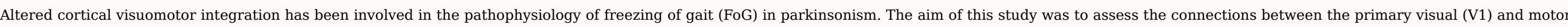

(M1) areas with a paired-pulse, twin-coil transcranial magnetic stimulation (TMS) technique in patients with FoG.

Methods

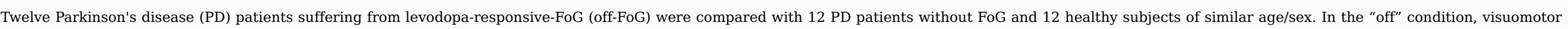

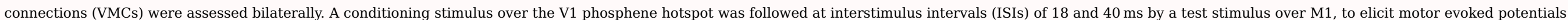
(MEPs) in the contralateral first dorsal interosseous muscle.

Results

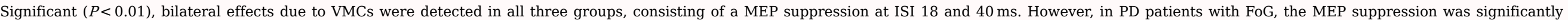
$(P<0.05)$ enhanced, both at ISI $18-40 \mathrm{~ms}$, in comparison with the other two groups. The phenomenon was limited to the right hemisphere.

Conclusions

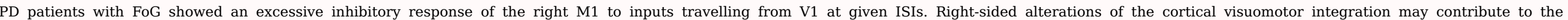
pathophysiology of FoG.

Keywords: Freezing of gait; Motor cortex; Parkinson's disease; Transcranial magnetic stimulation; Visual cortex; Visuomotor integration

\section{Introduction}

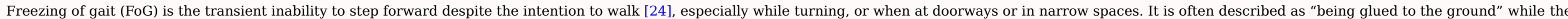




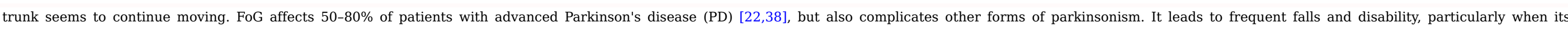

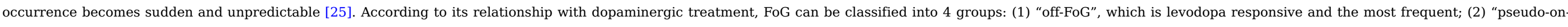

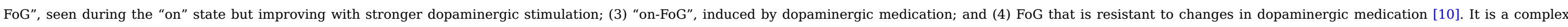

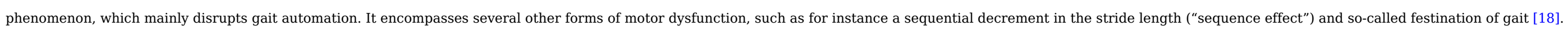

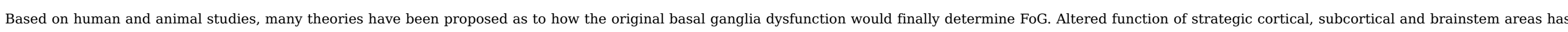

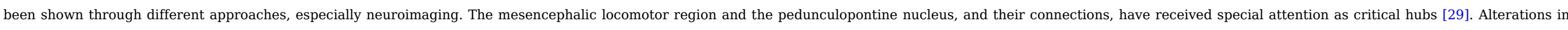
sensory (visual, proprioceptive) processing and spatiotemporal perception have been also described [1,12].

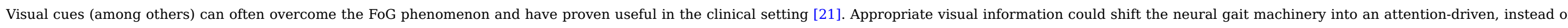

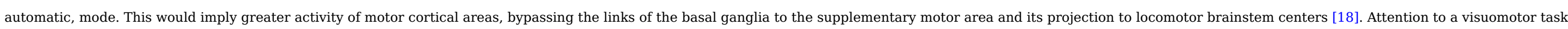
(previously automated) implied a different physiological behaviour of the primary motor area (M1) in PD patients as compared with controls [40].

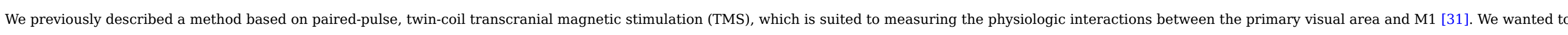

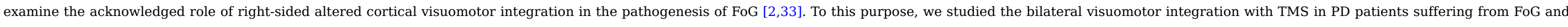
compared them to PD patients without FoG and to healthy controls.

\section{Methods}

\section{Participants}

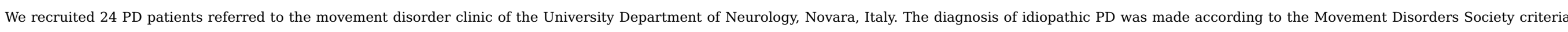

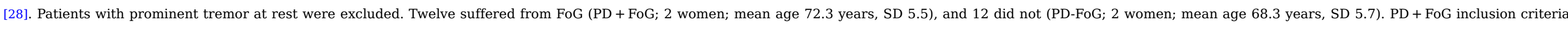

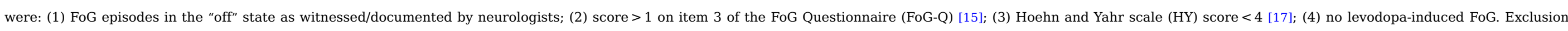
criteria were as follows: a diagnosis of atypical parkinsonism, a Mini Mental State Examination (MMSE) [14] score $\leq 24$ and other comorbidities negatively influencing walking.

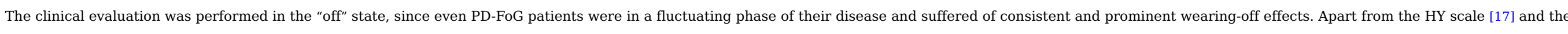

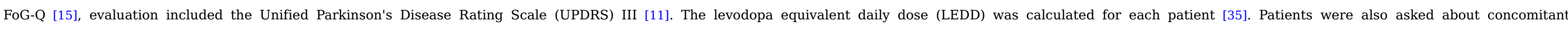

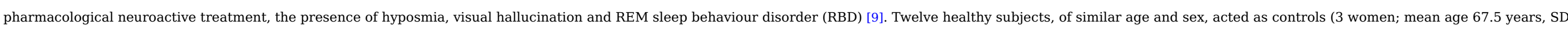

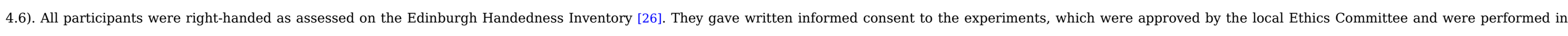
accordance with the Declaration of Helsinki. The main features of the participants are reported in Table 1.

Table 1 Main features of the participants.

\begin{tabular}{|c|c|c|c|c|}
\hline & $\begin{array}{l}\text { Healthy subjects } \\
\quad(n=12)\end{array}$ & $\begin{array}{l}\text { PD-FoG } \\
(n=12)\end{array}$ & $\begin{array}{c}\mathrm{PD}+\mathrm{FoG} \\
(n=12)\end{array}$ & $P$-value \\
\hline Gender M/F (\%) & $9 / 3(75 / 25)$ & $10 / 2(83 / 17)$ & $10 / 2(83 / 17)$ & \\
\hline Age & $\begin{array}{l}67.50 \pm 4.58 \\
(62-75)\end{array}$ & $\begin{array}{l}68.25 \pm 5.69 \\
(60-78)\end{array}$ & $\begin{array}{l}72.25 \pm 5.53 \\
(64-81)\end{array}$ & n.s. ${ }^{a}$ \\
\hline More affected PD side right/left & - & $5 / 7$ & $7 / 5$ & \\
\hline Disease duration (ys) & - & $\begin{array}{l}5.33 \pm 4.31 \\
(2-16)\end{array}$ & $\begin{array}{l}8.17 \pm 3.27 \\
(4-15)\end{array}$ & $0.028^{b}$ \\
\hline $\mathrm{H} \& \mathrm{Y}$ & - & $\begin{array}{l}1.50 \pm 0.48 \\
(1-2)\end{array}$ & $\begin{array}{l}1.96 \pm 0.69 \\
(1-3)\end{array}$ & $0.160^{\mathrm{b}}$ \\
\hline
\end{tabular}




\begin{tabular}{|c|c|c|c|c|}
\hline UPDRS III "off" & - & $\begin{array}{l}13.50 \pm 6.27 \\
(6-29)\end{array}$ & $\begin{array}{l}20.42 \pm 11.35 \\
(5-50)\end{array}$ & $0.045^{b}$ \\
\hline FoG-Q & - & $\begin{array}{l}0.42 \pm 0.67 \\
(0-2)\end{array}$ & $\begin{array}{l}11.08 \pm 5.12 \\
(4-22)\end{array}$ & $<0.001^{b}$ \\
\hline LEDD & - & $\begin{array}{l}415.75 \pm 257.68 \\
(100-975)\end{array}$ & $\begin{array}{l}843.08 \pm 273.29 \\
(360-1430)\end{array}$ & $0.001^{b}$ \\
\hline
\end{tabular}

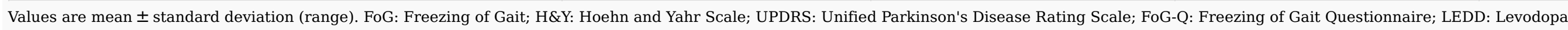
Equivalent Daily Dose; n.s.: not significant.

a Kruskal-Wallis test.

b Mann-Whitney test.

\section{Transcranial magnetic stimulation (TMS)}

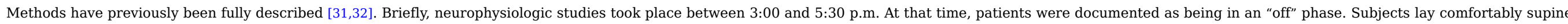

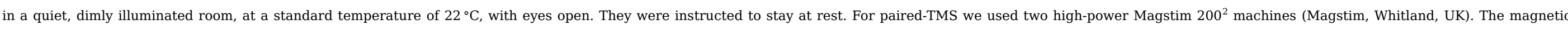
stimulus had a nearly monophasic pulse configuration with a rise time of $\sim 100 \mu \mathrm{s}$, decaying back to zero over $\sim 0.8$ us. The stimulators were connected to a figure-of-eight coil (outer winding diameter 70 mm).

\section{Test stimuli (TS)}

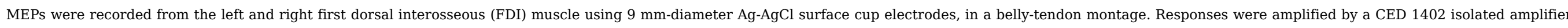

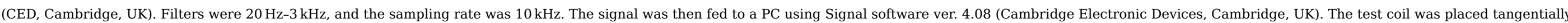

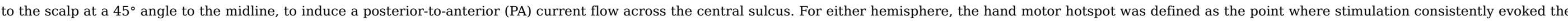

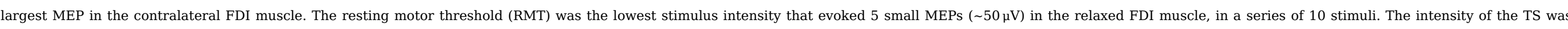
finally adjusted to evoke a MEP of $\sim 1 \mathrm{mV}$ peak-to-peak amplitude in the relaxed FDI.

\section{Conditioning stimuli (CS)}

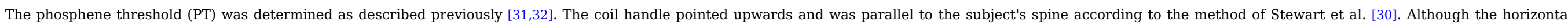

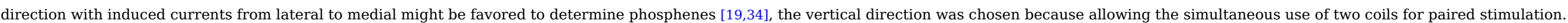

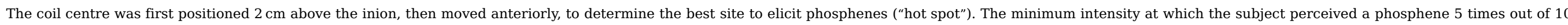
stimuli was the PT. The intensity of the CS was adjusted to be $90 \%$ PT.

\section{Experimental procedure}

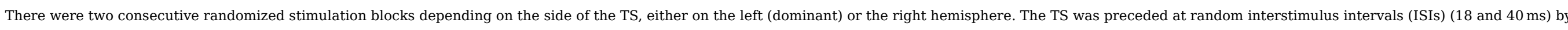

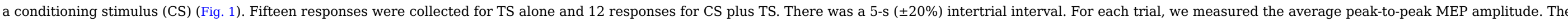
conditioned MEP was expressed as a percentage of the unconditioned MEP size. Measurements were performed via the Signal software ver. 4.08 (Cambridge Electronic Devices, Cambridge, UK). 


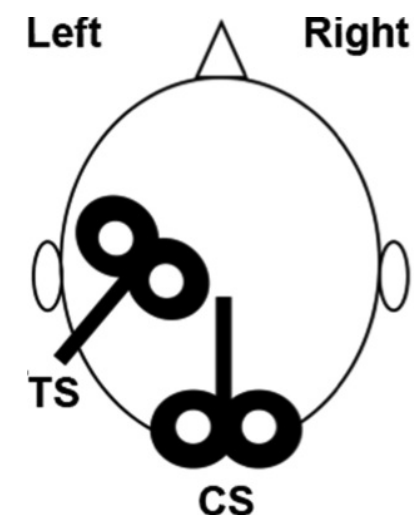

CS

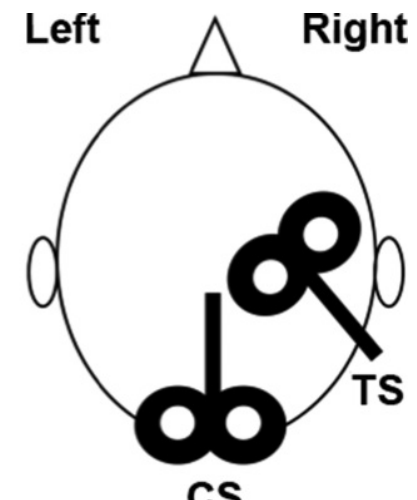

CS

Figure 1 Experimental setting of the study. Coil positions over a skull sketch. TS: test stimulus, delivered over the hand motor area (left or right); CS: conditioning stimulus, delivered over the phosphene hotspot over the visual cortex.

\section{Data analysis}

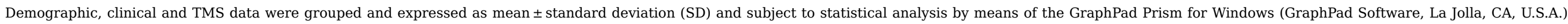

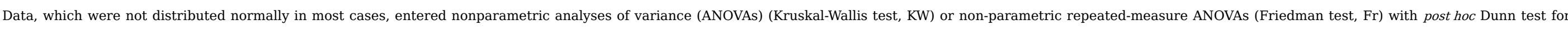

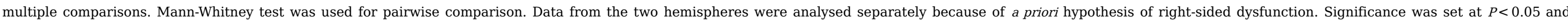
Bonferroni corrections of the $P$-values were applied throughout.

Spearman's rho was applied to study correlations between the clinical and the paired-pulse TMS variables. A $P$-value $<0.05$ (corrected for multiple comparisons) was considered significant.

\section{Results}

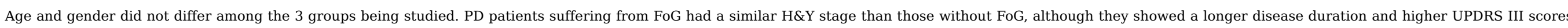

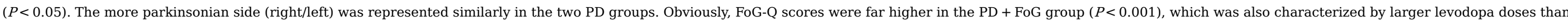
PD-FoG $(P=0.001)$ (Table 1).

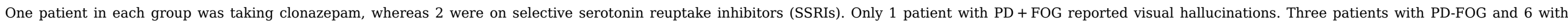
PD + FOG reported RBD. Seven patients in each group reported hyposmia.

Concerning baseline TMS measures, no significant differences in RMT, test MEP amplitude or PT were detected among the groups (Table 2).

Table 2 Physiological (TMS) data at baseline evaluation (mean \pm standard deviation).

\section{alt-text: Table 2}

\begin{tabular}{|c|c|c|c|c|}
\hline & $\begin{array}{l}\text { Healthy subjects } \\
\qquad(n=12)\end{array}$ & $\begin{array}{l}\text { PD-FoG } \\
(n=12)\end{array}$ & $\begin{array}{c}\mathrm{PD}+\mathrm{FoG} \\
(n=12)\end{array}$ & $P$ value ${ }^{\text {a }}$ \\
\hline RMT (R) & $\begin{array}{l}42.67 \pm 8.79 \\
(33-66)\end{array}$ & $\begin{array}{l}37.42 \pm 5.93 \\
(30-49)\end{array}$ & $\begin{array}{l}41.42 \pm 9.39 \\
(28-57)\end{array}$ & 0.327 \\
\hline $\mathrm{SI}_{1 \mathrm{mV}}(\mathrm{R})$ & $\begin{array}{l}53.17 \pm 13.09 \\
(38-74)\end{array}$ & $\begin{array}{l}43.25 \pm 8.21 \\
(33-60)\end{array}$ & $\begin{array}{l}51.25 \pm 14.32 \\
(36-85)\end{array}$ & 0.127 \\
\hline RMT (L) & $\begin{array}{l}40.42 \pm 11.35 \\
(26-63)\end{array}$ & $\begin{array}{l}37.67 \pm 8.26 \\
(25-49)\end{array}$ & $\begin{array}{l}40.75 \pm 7.83 \\
(29-53)\end{array}$ & 0.706 \\
\hline $\mathrm{SI}_{1 \mathrm{mV}}(\mathrm{L})$ & $\begin{array}{l}55.92 \pm 13.10 \\
(41-80)\end{array}$ & $\begin{array}{l}50.17 \pm 11.63 \\
(34-70)\end{array}$ & $\begin{array}{l}56.00 \pm 10.98 \\
(39-80)\end{array}$ & 0.558 \\
\hline
\end{tabular}




\begin{tabular}{|c|c|c|c|c|}
\hline PT & $\begin{array}{l}73.33 \pm 17.83 \\
(42-100)\end{array}$ & $\begin{array}{l}75.08 \pm 12.11 \\
(59-100)\end{array}$ & $\begin{array}{l}85.00 \pm 13.82 \\
(53-100)\end{array}$ & 0.122 \\
\hline $90 \% \mathrm{PT}$ & $\begin{array}{l}66.08 \pm 16.14 \\
(38-90)\end{array}$ & $\begin{array}{l}67.50 \pm 10.89 \\
(53-90)\end{array}$ & $\begin{array}{l}75.75 \pm 12.99 \\
(48-90)\end{array}$ & 0.107 \\
\hline MEP Test (R) & $\begin{array}{l}1.02 \pm 0.17 \\
(0.78-1.33)\end{array}$ & $\begin{array}{l}0.99 \pm 0.30 \\
(0.71-1.71)\end{array}$ & $\begin{array}{l}1.03 \pm 0.26 \\
(0.51-1.41)\end{array}$ & 0.683 \\
\hline MEP Test (L) & $\begin{array}{l}0.95 \pm 0.24 \\
(0.63-1.49)\end{array}$ & $\begin{array}{l}1.07 \pm 0.31 \\
(0.48-1.62)\end{array}$ & $\begin{array}{l}1.10 \pm 0.30 \\
(0.77-1.65)\end{array}$ & 0.180 \\
\hline
\end{tabular}

MEP: motor evoked potential; SI1 mV: intensity required to elicit a $1 \mathrm{mV}$ MEP; PT: phosphene threshold; RMT: resting motor threshold; R: right; L: left.

a Kruskal-Wallis test.

\section{Visuomotor connectivity in the left hemisphere}

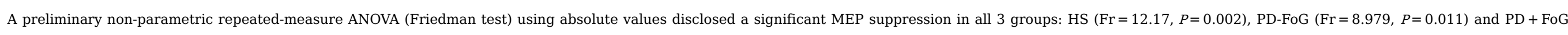

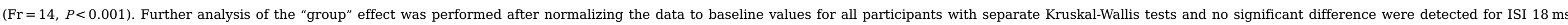
$(\mathrm{KW}=0.515, P=0.773)$ and ISI $40 \mathrm{~ms}(\mathrm{KW}=1.317, P=0.518)$.

\section{Visuomotor connectivity in the right hemisphere}

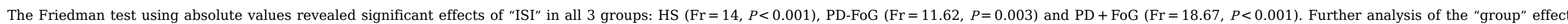

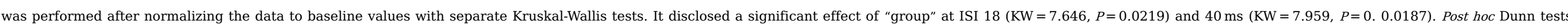

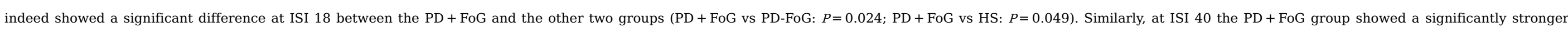
suppression compared with the other two groups (PD + FoG vs PD-FoG: $P=0.034$; PD + FoG vs HS: $P=0.025$ ) (Figs. $2 \mathrm{~B}$ and 3 ).

A Left hemisphere

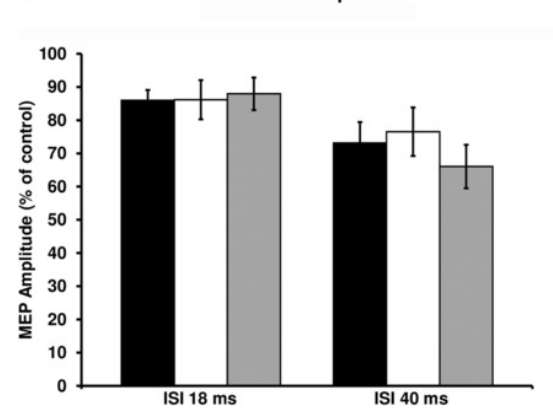

B Right hemisphere

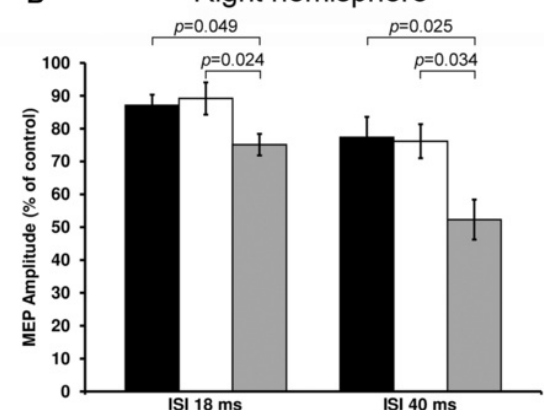

Figure 2 Visuomotor connectivity (VMC) in subjects at rest. Panel A: left hemisphere VMC.
expressed as a percentage of control. Errors bars indicate standard error of the mean (SEM). 


\section{PD+FoG}

\section{PD-FoG}

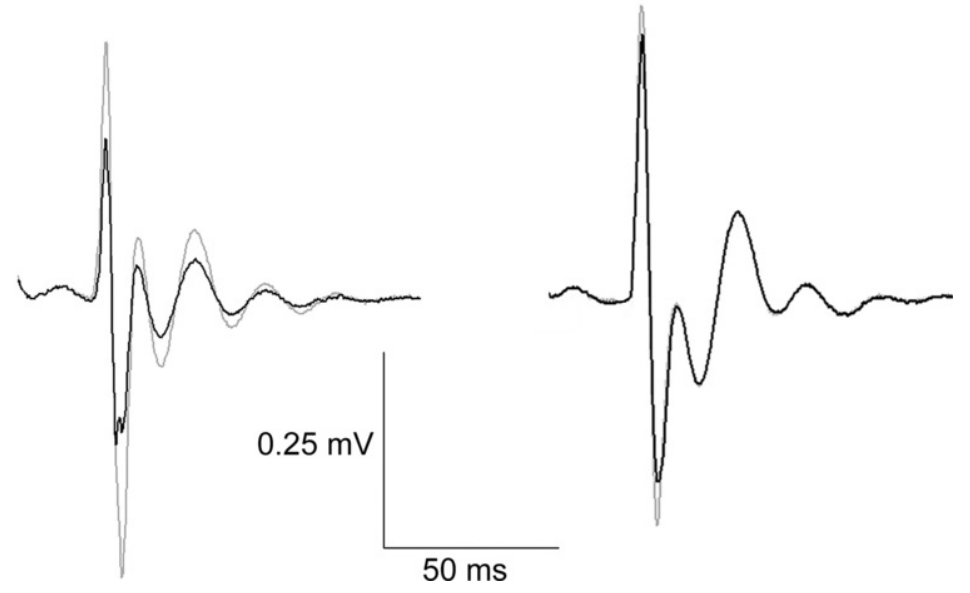

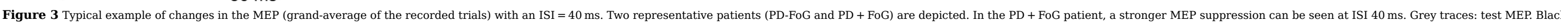
traces: conditioned MEP.

\section{Interhemispheric comparison}

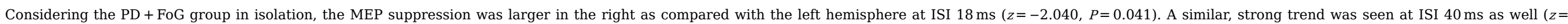
$-1.883, P=0.060)$. No significant interhemispheric differences were detected considering the HS and PD-FoG groups $(P>0.05)$.

\section{Clinical-neurophysiological correlations}

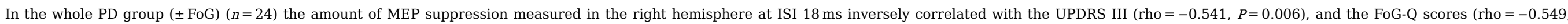

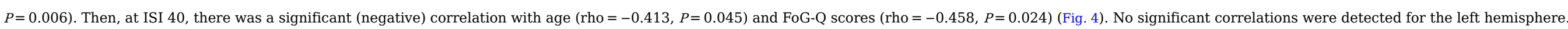



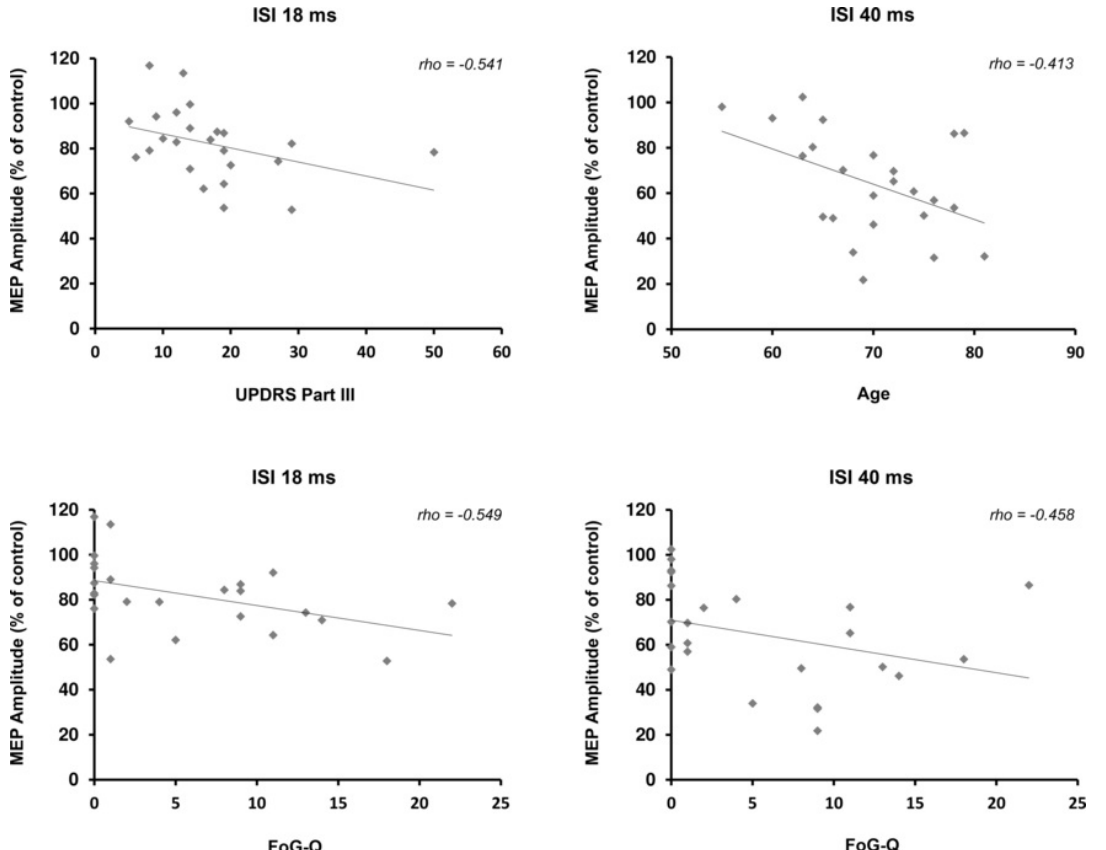

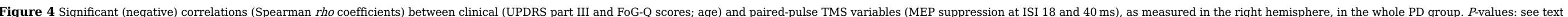

\section{Discussion}

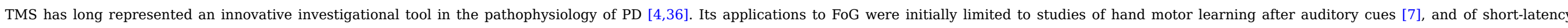

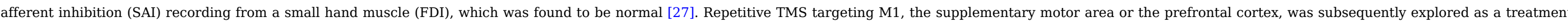
approach to FoG with somewhat controversial results [8,20,23].

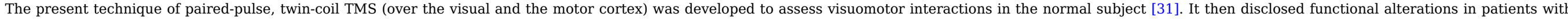

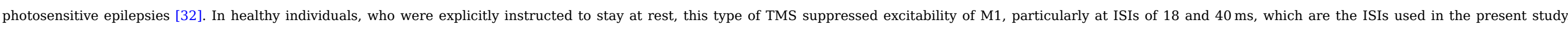

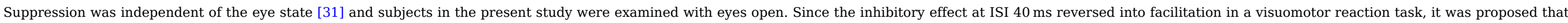
when movement occurs, the visuomotor interaction becomes excitatory, "particularly if vision is actively being used to control the movement" [31].

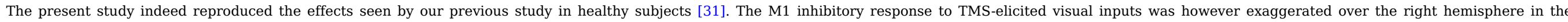

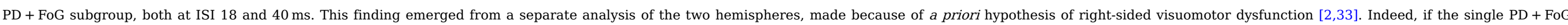

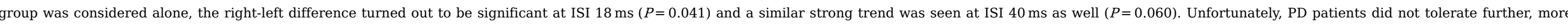

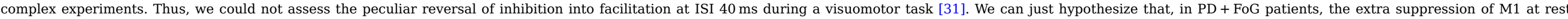

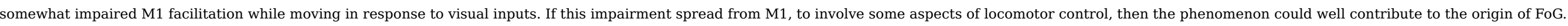

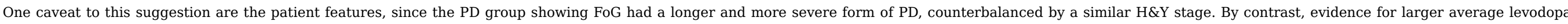

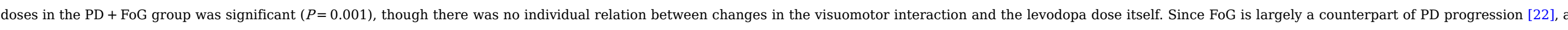

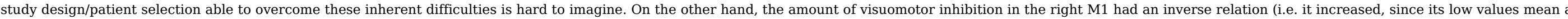

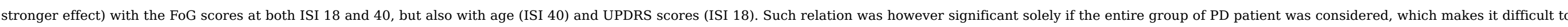

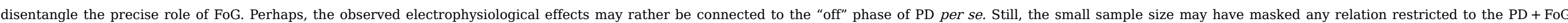




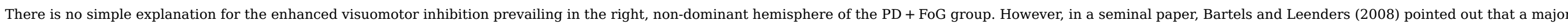

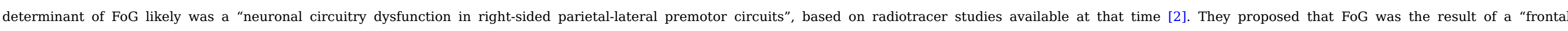

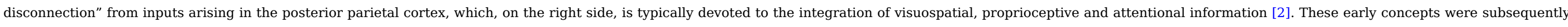

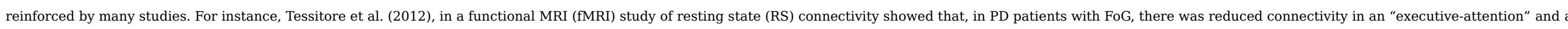

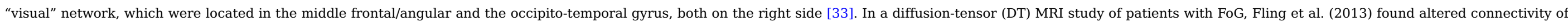

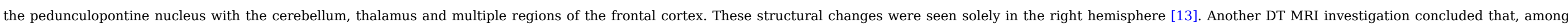

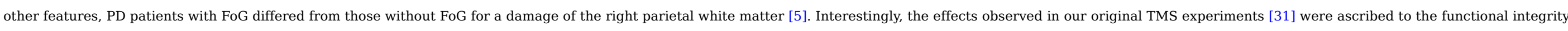

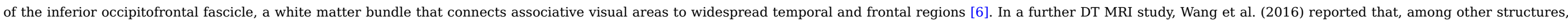

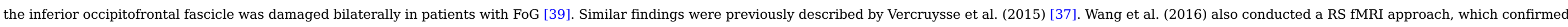

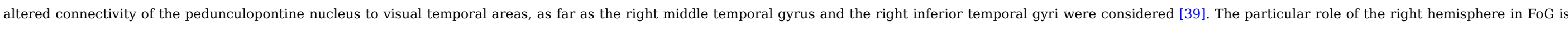
lately emphasized by Bharti et al. (2019), who used much similar methods [3].

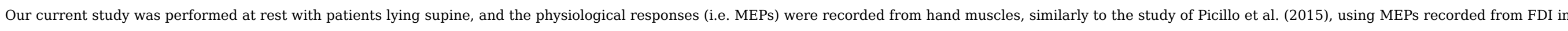

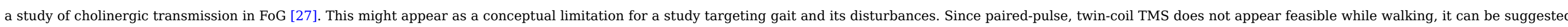

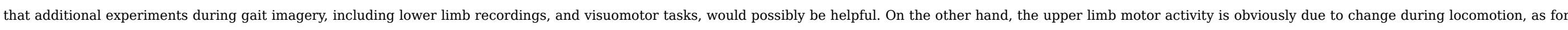
arm swings.

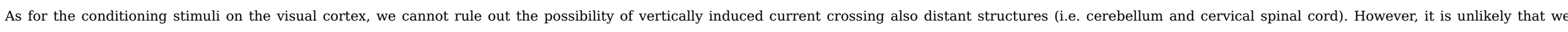

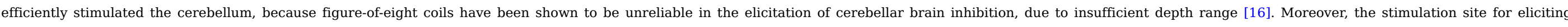

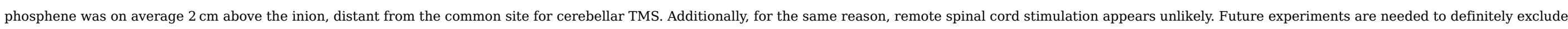
the eventual role of remote cerebellum or spinal cord stimulation.

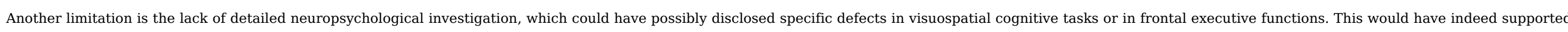

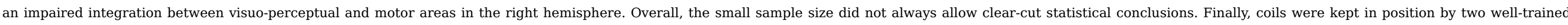
experimenters. However, a neuronavigation system would have been useful for the evaluation of the visual cortex target and for keeping the coil position stable over the whole experiment.

\section{Conclusions}

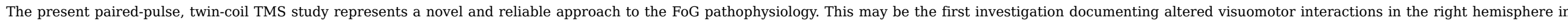
patients with FoG, in terms of electrophysiologic changes.

\section{Funding}

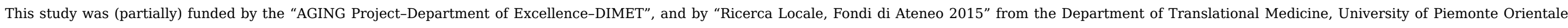
Novara, Italy.

\section{Disclosure of interest}

The authors declare that they have no competing interest.

\section{References}

[1] Q.J. Almeida and C.A. Lebold, Freezing of gait in Parkinson's disease: a perceptual cause for a motor impairment?, J Neurol Neurosurg Psychiatry 81, $2010,513-518$. 
[2] A.L. Bartels and K.L. Leenders, Brain imaging in patients with freezing of gait, Mov Disord 23, 2008, 461-467.

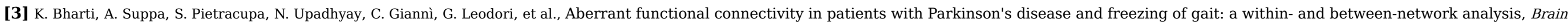
Imaging Behav 2019, https://doi.org/10.1007/s11682-019-00085-9, [in press].

[4] R. Cantello, R. Tarletti and C. Civardi, Transcranial magnetic stimulation and Parkinson's disease, Brain Res Brain Res Rev 38, $2002,309-327$.

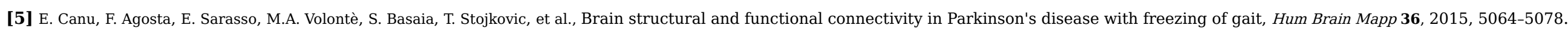

[6] M. Catani, R.J. Howard, S. Pajevic and D.K. Jones, Virtual in Vivo interactive dissection of white matter fasciculi in the human brain, Neuroimage 17, 2002 , 77-94.

[7] T. Chuma, M. Faruque Reza, K. Ikoma and Y. Mano, Motor learning of hands with auditory cue in patients with Parkinson's disease, J Neural Transm 113, 2006, 175-185.

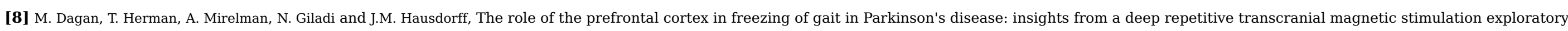
study, Exp Brain Res 235, 2017, 2463-2472.

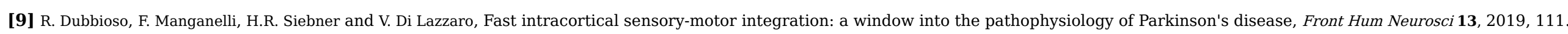

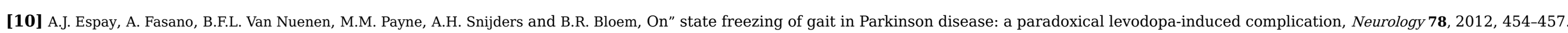

[11] S. Fahn and R.L. Elton, The Unified Parkinson's Disease Rating Scale (UPDRS), Rev Neurol (Paris) 156, 2000, 534-541.

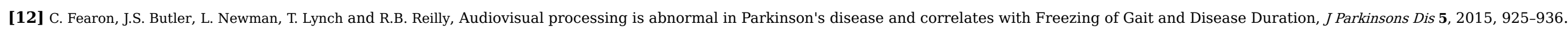

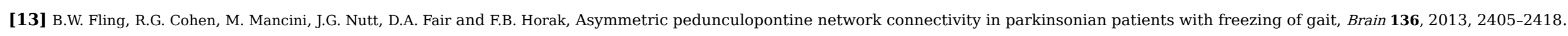

[14] M. Folstein and S. Folstein, A practical method for grading the cognitive state of patients for the clinician, J Psychiatr Res 12, 1975, 189-198.

[15] N. Giladi, H. Shabtai, E.S. Simon, S. Biran, J. Tal and A.D. Korczyn, Construction of freezing of gait questionnaire for patients with Parkinsonism, Park Relat Disord 6, 2000, 165-170.

[16] R.M. Hardwick, E. Lesage and R.C. Miall, Cerebellar transcranial magnetic stimulation: the role of coil geometry and tissue depth, Brain Stimul 7, 2014, 643-649.

[17] M.M. Hoehn and M.D. Yahr, Parkinsonism: onset, progression, and mortality. 1967, Neurology 57, 2001, 11-26.

[18] R. Iansek and M. Danoudis, Freezing of gait in Parkinson's disease: its pathophysiology and pragmatic approaches to management, Mov Disord Clin Pract 4, $2017,290-297$.

[19] T. Kammer, S. Beck, M. Erb and W. Grodd, The influence of current direction on phosphene thresholds evoked by transcranial magnetic stimulation, Clin Neurophysiol 112, 2001, 2015-2021.

[20] S.J. Kim, S.H. Paeng and S.Y. Kang, Stimulation in supplementary motor area versus motor cortex for freezing of gait in Parkinson's disease, J Clin Neurol 14, 2018 , 320-326.

[21] S.J. Lee, J.Y. Yoo, J.S. Ryu, H.K. Park and S.J. Chung, The effects of visual and auditory cues on freezing of gait in patients with parkinson disease, AmJ Phys Med Rehabil 91, 2012, 2-11.

[22] I.C. López, P.J.G. Ruiz, S.V.F. Del Pozo and V.S. Bernardos, Motor complications in Parkinson's disease: ten year follow-up study, Mov Disord 25, 2010 , 2735-2739.

[23] J. Ma, L. Gao, T. Mi, J. Sun, P. Chan and T. Wu, Repetitive transcranial magnetic stimulation does not improve the sequence effect in freezing of gait, Parkinsons Dis 2019, 2019 , 2196195.

[24] J. Nonnekes, A.H. Snijders, J.G. Nutt, G. Deuschl, N. Giladi and B.R. Bloem, Freezing of gait: a practical approach to management, Lancet Neurol 14, 2015 , 768-778.

[25] Y. Okuma, Proceedings of MDPD 2013 freezing of gait and falls in Parkinson's disease, J Park Dis 4, 2014, 255-260.

[26] R.C. Oldfield, The assessment and analysis of handedness: the Edinburgh inventory, Neuropsychologia 9, 1971, 97-113.

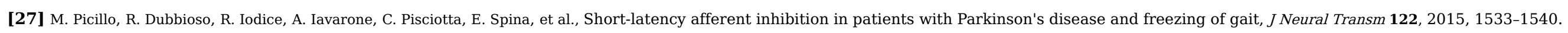


[28] R.B. Postuma, D. Berg, M. Stern, W. Poewe, C.W. Olanow, W. Oertel, et al., MDS clinical diagnostic criteria for Parkinson's disease, Mov Disord 30, 2015 , $1591-1601$.

[29] A.H. Snijders, K. Takakusaki, B. Debu, A.M. Lozano, V. Krishna, A. Fasano, et al., Physiology of freezing of gait, Ann Neurol 80, 2016, 644-659.

[30] L.M. Stewart, V. Walsh and J.C. Rothwell, Motor and phosphene thresholds: a transcranial magnetic stimulation correlation study, Neuropsychologia 39, 2001 , 415-419.

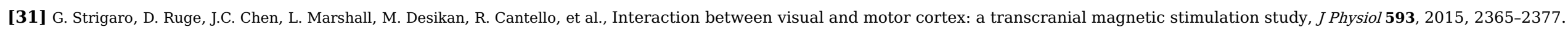

[32] G. Strigaro, L. Falletta, C. Varrasi, J.C. Rothwell and R. Cantello, Overactive visuomotor connections underlie the photoparoxysmal response. A TMS study, Epilepsia 56, 2015 , 1828-1835.

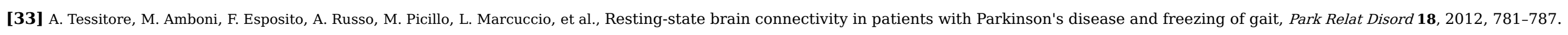

[34] A. Thielscher, A. Reichenbach, K. Uğurbil and K. Uludağ, The cortical site of visual suppression by transcranial magnetic stimulation, Cereb Cortex 20, 2010 , 328-338.

[35] C.L. Tomlinson, R. Stowe, S. Patel, C. Rick, R. Gray and C.E. Clarke, Systematic review of levodopa dose equivalency reporting in Parkinson's disease, Mov Disord 25, 2010, 2649-2653.

[36] K. Udupa and R. Chen, Motor cortical circuits in Parkinson disease and dystonia, Handb Clin Neurol 161, 2019, 167-186.

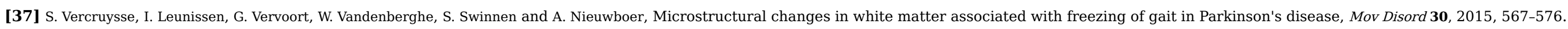

[38] C.C. Walton, J.M. Shine, J.M. Hall, C. O’Callaghan, L. Mowszowski, M. Gilat, et al., The major impact of freezing of gait on quality of life in Parkinson's disease, J Neurol 262, 2015, 108-115.

[39] M. Wang, S. Jiang, Y. Yuan, L. Zhang, J. Ding, J. Wang, et al., Alterations of functional and structural connectivity of freezing of gait in Parkinson's disease, J Neurol 263, 2016, 1583-1592.

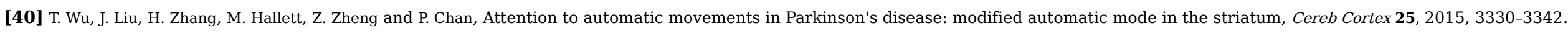

\section{Queries and Answers}

Query: The author names have been tagged as given names and surnames (surnames are highlighted in teal color). Please confirm if they have been identified correctly. Answer: Yes

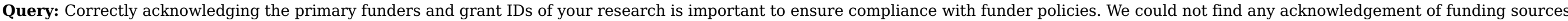
in your text. Is this correct?

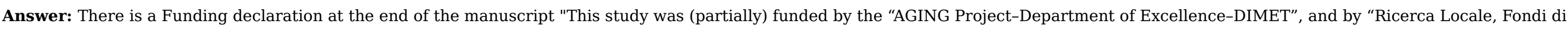
Ateneo 2015” from the Department of Translational Medicine, University of Piemonte Orientale, Novara, Italy."

Query: Please supply the volume and page range for reference [3].

Answer: Sorry, there is no volume and page range because it is an Online ahead of print paper. 